\title{
ANALISIS PENERAPAN METODE TABARAK MENGHAFAL AL-QUR'AN JUZ 30 DI SEKOLAH TAHFIDZ AL-HUSNA BALITA DAN ANAK MAKASSAR
}

\author{
Tendri Herma \\ Jurusan Pendidikan Islam Anak Usia Dini \\ Fakultas Tarbiyah dan Keguruan, UIN Alauddin Makassar \\ Email: hermaabdullah551097@gmail.com \\ Umi Kusyairy \\ Jurusan Pendidikan Islam Anak Usia Dini \\ Fakultas Tarbiyah dan Keguruan, UIN Alauddin Makassar \\ Email: umi. kusyairi@uin-alauddin.ac.id \\ Muh. Rusdi T. \\ Jurusan Pendidikan Islam Anak Usia Dini \\ Fakultas Tarbiyah dan Keguruan, UIN Alauddin Makassar \\ Email: rusdithahir@gmail.com
}

\begin{abstract}
Abstrak
Penelitian kualitatif ini bertujuan untuk mengetahui gambaran, faktor pendukung serta faktor penghambat penerapan metode Tabarak dalam menghafal al-Qur'an pada juz 30 di Sekolah Tahfidz Al-Husna Balita dan Anak Makassar. Sumber data penelitian adalah ketiga ustadzah yang mengajar metode Tabarak kelas Balita, kepala sekolah dan ustadzah berlisensi yang memvalidasi prosesnya. Instrumen penelitian berupa observasi, wawancara dan dokumentasi yang dianalisis menggunakan model Miles dan Huberman (reduksi data, penyajian data, dan penarikan kesimpulan). Hasil penelitian menunjukkan bahwa: 1) proses pembelajaran metode Tabarak dalam menghafal al-Qur'an di Sekolah Tahfidz Al-Husna Balita dan Anak Makassar memiliki buku pedoman khusus yang disusun oleh Kamil el-Laboody. Pelaksanaannya dengan mentalqinkan anak bacaan al-Qur'an dan muraja'ah hafalan dengan memperdengarkan murattal yang memanfaatkan media elektronik (TV, MP3, Speaker, dan MIC); 2) faktor pendukung yaitu ruangan kondusif, ustadzah yang ramah, tahsin dan tahfidz ustadzah yang bagus, sarana dan prasarana memadai, serta dukungan orangtua dalam menghafal al-Qur'an; 3) faktor penghambat yaitu anak kurang fokus karena bermain dalam kelas, anak yang terlambat atau tidak hadir ke sekolah, kesibukan orangtua sehingga kurang terkontrolnya muraja'ah hafalan anak di rumah, ketiga ustadzah yang belum berlisensi, serta sekolah tidak menerapkan 2 file video yang ada pada metode Tabarak (Tikror dan muraja'ah) sehingga tidak maksimal terutama kedisiplinan anak.
\end{abstract}

Kata Kunci: Al-Qur'an, Menghafal, Metode Tabarak, Pendidikan Anak Usia Dini 


\begin{abstract}
This qualitative research aims to recognize the description of supporting and inhibiting factors of the application of the Tabarak method in memorizing alQur'an of juz 30 at Tahfidz School Al-Husna for Toddlers and Children Makassar. The sources of research data were the three teachers who teach the Tabarak method for toddlers, school principal and licensed teacher who validated the process. The research instruments such as guidelines for observation, interviews and documentation were analyzed using the Miles and Huberman models (data reduction, data display, and drawing conclusions). The results showed that: 1) the learning process of Tabarak method in memorizing al-Qur'an at the Tahfidz School Al-Husna for Toddler and Children Makassar has a special guidebook composed by Kamil elLaboody. This program implemented by reconciled the child with reciting the al-Qur'an and reviewing their memorization by playing murattal with utilizing electronic media (TV, MP3, Speaker, and MIC); 2) supporting factors were going classrooms climate, friendly teachers, teachers with very good reciting and memorizing al-Qur'an, adequate facilities and infrastructure, as well as parental support; 3) inhibiting factors were unfocusing in class because of frequently playing, children coming late or unpresent from school, busyness of parents reducing control in memorization of children at home, unlicensed teachers, and ignorances 2 existing video files in the Tabarak method (repetition and reviewing). Therefore, the children could not reach the optimum result and also they did not stick on the rules.
\end{abstract}

Keywords: Al-Qur'an, Memorizing, Tabarak Method, Early Childhood Education Programs

\title{
PENDAHULUAN
}

Anak usia dini merupakan masa keemasan atau sering disebut golden age. Pada masa ini otak anak mengalami perkembangan paling cepat sepanjang sejarah kehidupannya. Hal ini berlangsung pada saat anak dalam kandungan hingga usia dini, yaitu usia nol sampai enam tahun. Namun, masa bayi dalam kandungan hingga lahir, sampai usia empat tahun adalah masa-masa yang paling menentukan. Periode ini, otak anak sedang mengalami pertumbuhan yang sangat pesat. Oleh karena itu memberikan perhatian lebih terhadap anak di usia dini merupakan keniscayaan. Wujud perhatian diantaranya dengan memberikan pendidikan baik langsung dari orang tuanya sendiri maupun melalui lembaga Pendidikan anak usia dini (Mufarizudin, 2018). Masa balita merupakan masa emas yang tidak akan berulang, karena merupakan masa paling penting dalam pembentukan dasar-dasar kepribadian, kemampuan berpikir, kecerdasan, keterampilan dan kemampuan bersosialisasi (Yulidesni, Kurniah, dan Novrinda, 2017). Pada masa tersebut merupakan masa emas (golden age), karena anak mengalami pertumbuhan dan perkembangan yang cukup pesat dan tidak tergantikan pada masa mendatang. Menurut banyak penelitian bidang neurologi ditemukan bahwa 50\% kecerdasan 
anak terbentuk pada kurun waktu 4 tahun pertama. Setelah usia 8 tahun, perkembangan otaknya mencapai $80 \%$ dan pada usia 18 tahun mencapai $100 \%$ (Khomaeny, Rusmana, Hikmah, Yunitasari, dan Maulana, 2018).

Pendidikan Anak Usia Dini (PAUD) merupakan peletak dasar pertama dan utama dalam pengembangan pribadi anak, baik berkaitan dengan karakter, kemampuan fisik, kognitif, bahasa, seni, sosial emosional, spiritual, disiplin diri, konsep diri, maupun kemandirian dan panca indra. PAUD memegang peranan yang sangat penting dan menentukan bagi sejarah perkembangan anak selanjutnya, karena merupakan fondasi bagi dasar kepribadian anak. PAUD sangat menentukan kesuksesan seseorang di masa depan, bagaimana seseorang merespon berbagai permasalahan yang dihadapi dalam setiap langkah kehidupan sangat ditentukan oleh pengalaman dan pendidikan yang diperolehnya pada saat usia dini (Hasyim, 2015). Undang-Undang No 20 Tahun 2003 memuat tentang Sistem Nasional Pasal 1 ayat 14 menyatakan bahwa pendidikan anak usia dini (PAUD) adalah suatu upaya pembinaan yang ditunjukkan kepada anak sejak lahir sampai dengan usia enam tahun yang dilakukan melalui pemberian rangsangan pendidikan untuk membantu peertumbuhan dan perkembangan jasmani dan rohani, agar anak memiliki kesiapan dalam memasuki pendidikan lebih lanjut, baik pendidikan secara formal disekolah maupun secara non formal (Ariyanti, 2016).

Banyak anggapan masyarakat yang menyatakan bahwa anak-anak usia dini belum perlu mengenyam pendidikan formal, khususnya belajar menghafal alQur'an. Karena usia dini itu waktunya untuk bermain, yakni main menjadi sarana untuk anak belajar sehingga dapat dikatakan bahwa belajar anak usia dini adalah bermain (Latif, Zukhairina, Zubaidah, dan Afandi, 2016). Jadi, tidak perlu membebani mereka dengan hafalan al-Qur'an dan sejenisnya. Tapi faktanya, mayoritas ulama-ulama besar hafal al-Qur'an pada usia dini, ketika mereka masih kanak-kanak. Sebut saja Imam Syafi'l, Imam Bukhari, Yusuf Qadhawi dan banyak lagi. Menghafal di usia dini juga merupakan tradisi para ulama (Ahmad, 2017). Menghafal pada saat usia dini sangatlah enak karena jika semakin dini hafalannya selesai, maka mereka juga akan punya waktu untuk mempelajari banyak hal lain. Pada saat itu apapun yang mereka pelajari, mereka punya modal dasar berupa hafalan dalam dada mereka (Masyhud dan Husnur, 2016).

Pendidikan anak usia dini adalah hal yang penting dan sangat ditekankan dalam menghafal. Dalam hal ini pendidikan anak usia dini diatur dalam UU No 20 Tahun 2003 tentang Sistem Pendidikan Nasional yang bertujuan untuk mengembangkan potensi peserta didik agar menjadi manusia yang beriman dan bertaqwa kepada Allah swt (Samuel, 2017). Penting bagi orangtua untuk mengenalkan dan mendekatkan anaknya dengan al-Qur'an, karena al-Qur'an merupakan sumber utama dalam Islam yang mencakup semua aspek kehidupan dan berfungsi sebagai pedoman dan petunjuk bagi semua manusia. Semua umat Islam diwajibkan menghafal al-Qur'an minimal pada juz 30, karena merupakan 
bacaan dalam shalat. Al-Qur'an adalah mukjizat sepanjang zaman dan Allah swt telah menjadikannya mudah agar anak balita pun bisa menghafalnya.

Al-Qur'an merupakan bahasa Arab yang artinya bacaan atau dibaca. Secara bahasa al-Qur'an adalah bacaan yang disampaikan dengan berulang. Pengertian al-Qur'an ditinjau dari segi istilah menurut para ahli. Manna' Khathan mengungkapkan bahwa al-Qur'an adalah kitab Allah yang diturunkan kepada Nabi Muhammad SAW dan siapa yang membacanya akan mendapat pahala. Al-Jurjani menjelaskan bahwa pengertian al-Qur'an adalah kalam Allah swt yang diturunkan kepada Rasulullah saw yang ditulis dalam mushaf dan diriwayatkan secara mutawatir tanpa keraguan (Gade, 2014). Kemudian Abu Syabbah mendefinisikan al-Qur'an sebagai kitab yang diturunkan kepada Nabi Muhammad saw yang diriwayatkan secara bersama, yakni dengan penuh kepastian dan kesesuaian apa yang telah diturunkan kepada Nabi Muhammad saw yang ditulis pada mushaf mulai dari surah Al-Fatihah sampai surah terakhir yaitu An-Nas (Iryani, 2017).

Selanjutnya, metode dari segi bahasa berasal dari dua kata yaitu metha (melalui) dan hodos (jalan, cara). Dengan demikian dapat diartikan bahwa metode adalah cara atau jalan yang dilalui untuk mencapai suatu tujuan (Khoiriyah, 2016). Metode merupakan suatu alat dalam pelaksanaan pendidikan, yakni yang digunakan dalam penyampaian materi tersebut. Materi pelajaran yang mudah pun kadang-kadang sulit berkembang dan sulit diterima oleh peserta didik, karena cara atau metode yang digunakannya kurang tepat. Namun, sebaliknya suatu pelajaran yang sulit akan mudah diterima oleh peserta didik, karena penyampaian dan metode yang digunakan mudah dipahami, tepat dan menarik (Maesaroh, 2013).

Tahfidz berasal bahasa arab, yang bentuknya berupa dari fi'il (kata kerja): hafizha - yahfazhu - hifzhan. Jika dikatakan, hafizha asysyai'a, artinya menjaga (jangan sampai rusak), memelihara dan melindungi. Hafizha ad-darsa, artinya menghafal. Dari sini, dapat diketahui bahwa kata hafizha - yahfazhu - hifzhan dalam bahasa Indonesia artinya adalah menghafal (Aziz, 2017). Menghafal adalah suatu metode yang digunakan untuk mengingat kembali sesuatu yang pernah dibaca secara benar seperti apa adanya. Metode tersebut banyak digunakan dalam usaha untuk menghafal al-Qur'an dan al-Hadits (Masduki, 2018).

Menghafalkan al-Qur'an merupakan salah satu bentuk interaksi umat Islam dengan al-Qur'an yang telah berlangsung secara turunmenurun sejak al-Qur'an pertama kali turun kepada Nabi Muhammad SAW. hingga sekarang dan masa yang akan datang. Allah SWT. telah memudahkan al-Qur'an untuk dihafalkan, baik oleh umat Islam yang berasal dari Arab maupun selain Arab yang tidak mengerti arti kata-kata dalam al-Qur'an yang menggunakan bahasa Arab (Hidayah, 2017). Menghafal al-Quran tentu sangat utama bagi kaum muslim. Menghafal al-Qur'an membuktikan sebuah keteladanan kepada Nabi SAW. Dalam sebuah hadits pernah diceritakan kepada kita, bahwa Rasulullah SAW hampir setiap malam di bulan Ramadhan belajar al-Qur'an sekaligus mengecek hafalan beliau bersama malaikat 
Jibril. Selain dari bentuk keteladanan kepada Nabi, dengan menghafal al-Qur'an akan memudahkan seseorang dalam menguatkan argumentasi dalam menjalankan dakwahnya. Lebih dari itu lagi adalah sebagai salah satu dasar cara menjaga keontentikan al-Qur'an, hal ini dapat dilihat dari kisah-kisah sahabat dan para tabi'in terdahulu berlomba-lomba menghafalkan al-Qur'an. Secara tekstual tidak didapatkan nash atau dalil yang tegas perintah menghafalkan al-Qur'an. Menghafalkan al-Qur'an termasuk perkara kifayah artinya jika sebagian orang sudah melakukan hal ini, maka yang lain gugur kewajibannya. Tetapi yakinilah bahwa segala sesuatu yang datangnya dari kehendak Allah SWT tentu memiliki keutamaan-keutaaan yang mulia (Hariyanti, 2017).

Adapun pada proses menghafal menggunakan metode Tabarak terdiri dari 7 level. Metode ini terilhami oleh pengalaman Dr. Kamil el-Laboody dalam mengarahkan anaknya yang bernama Tabarak. Awalnya, anak lebih banyak diperdengarkan baik dari ustadzah maupun orang tuanya atau murattal. Satu ayat bisa diulang sampai 3 kali yang diputar sebanyak 20 kali dan anak diminta untuk mendengarkan dengan seksama dan melihat bagaimana ustadzah atau orangtua mengucapkan tiap kata. Dalam menghafal metode tabarak ini, awalnya Dr. Kamil el-Laboody menerapkan metode ini kepada ketiga anaknya yaitu (Tabarak, Yazid dan Zeenah) yang pada saat itu, belum bisa menghafal al-Qur'an dengan cara membacanya. Bacaan al-Qur'an hanya diperdengarkan sembari mulai diperkenalkan pula pada huruf dan harakat al-Qur'an. Yang dimulai dari surahsurah pendek atau juz 30. Saat di rumah beliau menalqinkan surah-surah kepada Tabarak, setelah anak diminta untuk menghafalkan surah yang telah dihafalnya. Apabila Tabarak berhasil menghafal surahnya, maka orangtuanya akan memberikannya hadiah yang disukai oleh Tabarak. Selain itu terdapat makanan khusus berupa susu, madu, dan kurma untuk menjaga stamina. Seperti itulah cara Dr. Kamil el-Laboody beserta istrinya dalam mengajarkan menghafal al-Qur'an kepada anaknya (Masyhud dan Husnur, 2016).

Metode Tabarak ini mendominasi semua metode menghafal al-Qur'an karena metode Tabarak cara mengajarannya dan cara belajarnya itu dilakukan dengan santai tanpa adanya suatu paksaan serta dalam proses pembelajarannya audiovisual yaitu anak diputarkan murottal syekh-syekh terkenal menggunakan alat pendukung yaitu speaker dan TV dalam ruangan yang menggunakan AC, sehingga anak dapat berkonsentrasi dalam menghafal. Setelah itu, anak diminta untuk istirahat sambil muraja'ah hafalan kemarin sambil asisten gurunya menyediakan makanan Tabarak yakni kurma dan susu yang diberikan pada anak dengan cara antri. Setelah itu, anak kemudian diputarkan kembali surah yang tadi sampai anak mengingatnya. Sehingga, dari berbagai metode menghafal al-Qur'an yang dikembangkan oleh sekolah-sekolah tahfidz untuk memudahkan seseorang menghafal al-Qur'an diantaranya adalah metode Tabarak.

Adapun metode Tabarak yang diterapkan pada Sekolah Tahfidz Al-Husna 
Balita dan Anak Makassar merupakan salah satu jalan untuk mewujudkan harapan terbesar para orangtua muslim yaitu ingin menjadikan anaknya hafidz Qur'an pada usia dini. Namun, masih terdapat sejumlah hambatan dalam kemampuan anak untuk menghafal, sehingga perlu dianalisis lebih lanjut.

\section{METODE PENELITIAN}

Jenis penelitian ini mengunakan pendekatan kualitatif dengan jenis deskriptif. Subjek dalam penelitian ini sebanyak 5 orang yakni 3 orang ustadzah yang mengajar pada kelas balita, seorang kepala sekolah, dan seorang ustadzah berlisensi yang memvalidasi proses mengajar. Lokasi penelitian dilakukan pada Sekolah Tahfidz Al-Husna Balita dan Anak Makassar, yakni sejak pertengahan bulan februari hingga pertengahan bulan maret 2020.

Data ini dikumpulkan menggunakan teknik observasi, wawancara terstruktur dan dokumentasi. Dimana peneliti melakukan proses pengamatan di lapangan dengan mengumpulkan informasi yang diperlukan. Selain itu juga menggunakan wawancara terstruktur, peneliti membuat daftar pertanyaan yang akan diajukan kepada reponden lengkap dengan jabawabannya. Selain itu peneliti juga menggunakan dokumentasi guna mengumpulkan data baik dari buku, dokumen, dan pengamatan lapangan. Data yang sudah tersedia kemudian dianalisis menggunakan analisis deskriptif kualitatif. Data dianalisis menggunakan tiga tahap dalam model Miles dan Huberman yakni: reduksi data (mengumpulkan data dan informasi penting dari hasil observasi, wawancara, dan dokumentasi); penyajian data (rangkuman deskriptif dari hasil yang diperoleh untuk memudahkan rencana kerja selanjutnya); dan penarikan kesimpulan (menguji kesimpulan dengan membandingkan teori yang relevan, mengecek ulang hasil penelitian, serta membuat kesimpulan berupa temuan baru) (Sugiyono, 2016).

\section{HASIL DAN PEMBAHASAN}

Hasil penelitian menujukkan bahwa pada penerapan metode tabarak pada Sekolah Tahfidz Al-Husna Balita dan Anak Makassar, dengan teknik pengumpulan data yang digunakan adalah observasi, wawancara dan dokumentasi.

Program menghafal al-Qur'an pada anak usia dini di Sekolah Tahfidz Al-Husna Makassar dilaksanakan dengan menggunakan metode Tabarak. Program tersebut dilaksanakan dengan mengikuti bacaan al-Qur'an dan muraja'ah hafalan dengan memperdengarkan murattal. Aktivitas menghafal al-Qur'an memanfaatkan media elektonik (TV, MP3, Speaker, dan MIC). Pelaksanaannya yaitu anak berdoa bersama, melakukan senam ringan, kemudian diputarkan rekaman murattal juz 'amma yang dibacakan oleh para Syekh atau Qori, anak menyaksikan, mendengarkan dan megikuti rekamana tersebut bersama-sama yang diikuti oleh ustadzah, bacaan murattalnya diulang perayat sebanyak 3 kali dan diputarkan sebanyak 20 kali agar mudah tersimpan dalam memori anak dan berlanjut 
seterusnya sesuai dengan target yang dihafalkan pada setiap pertemuan mengikut pada timelite atau sejenis RPPH. Menghafal metode tabarak dimulai dari surah AlFatihah kemudian lanjut ke An-Naba sampai An-Nas. Apabila ada anak yang cara mengikutiya lantang (keras) maka anak tersebut mendapatkan bintang dari ustadzahnya begitupun seterusnya. Kemudian, ustadzah memberhentikan video murattal tersebut, ustadzah memutar surah melalui MP3 dan anak diminta untuk mengikuti/ murajaah hafalan yang telah dihafal pada pertemuan yang lalu yakni dari surah An-Naba-Al-Fajr. Setelah itu, anak diminta untuk mengantri sambil murajaahkan hafalannya pada pertemuan yang kemarin. Setelah murajaahkan hafalannya satu persatu, anak pun diminta untuk mengambil susu dan kurma yang telah disediakan dan menikmati tanpa berbicara apabila ada yang berbicara diberikan SP1 apabila anak masih mengulang maka makanannya diambil oleh ustadzah. Cara menghafal anak berbeda sesuai dengan daya ingatan anak, pelafalan serta umurnya. (hasil wawancara dengan $A B$ ).

Pada hasil penelitian diatas, penerapan metode Tabarak memiliki buku panduan khusus yang disusun oleh Kamil el-Laboody. Pada menghafal metode Tabarak ini terdiri dari 7 level. Satu ayat bisa diulang sampai 3 kali yang diputar sebanyak 20 kali dan anak-anak diminta untuk mendengarkan dengan seksama dan melihat bagaimana ustadzah atau orangtua mengucapkan tiap kata. Setelah itu, anak diminta untuk mengikuti surah yang ditalqinkan. Tabarak sendiri saat itu belum bisa menghafal al-Qur'an dengan cara membaca. Saat di rumah beliau menalqinkan surah-surah kepada anak. Bacaan al-Qur'an hanya diperdengarkan sembari mulai diperkenalkan pula pada huruf dan harakat al-Qur'an. Yang dimulai dari surah-surah pendek atau juz 30. Apabila Tabarak telah berhasil menghafal surah yang orang tuanya berikan, maka tabarak bebas memilih hadiah yang disukainya. Seperti itulah cara Kamil beserta istrinya dalam mengajarakan menghafal al-Qur'an kepada anaknya (Masyhud dan Husnur, 2016).

Adapun faktor pendukung penerapan metode Tabarak dalam menghafal alQur'an Juz 30 di Sekolah Tahfidz Al-Husna Balita dan Anak Makassar meliputi: 1) ruangan yang kondusif yakni nyaman, jauh dari keributan suara kendaraan, suasana yang tenang, serta tidak terdapat tempel-tempelan pada dinding ruangan agar fokus anak saat menghafal tidak mengarah ke sumber tempelan tersebut, 2) ustadzah yang ramah pada anak, 3) tahsin dan tahfidz ustadzah yang bagus, 4) sarana dan prasarana memadai, karena apabila tidak memadai maka fokus anak akan terganggu saat menghafal (MP3, MIC, AC, Toilet, karpet, dan lainnya); serta 5) dukungan orangtua dalam menghafal al-Qur'an;

kelima faktor pendukung tersebut merupakan hal yang memudahkan anak dalam menghafal ayat-ayat suci al-Qur'an serta membuat anak lebih aktif dalam memahami ayat suci al-Qur'an (hasil wawancara dengan AB). Hal ini dikuatkan oleh teori dari (Sayyid, 2013) yang mengatakan sebelum memulai hafalan hendaknya menyiapkan tempat yang nyaman, yang tidak terdapat suatu hal yang 
menghilangkan konsentrasi dan perhatian anak. Dalam kegiatan menghafal alQur'an digunakan media pembelajaran elektronik yakni TV yang membantu proses menghafal al-Qur'an pada anak, media yang digunakan berupa video dan murattal. (Qamariah dan Irsyad, 2016) menjelaskan pemanfaatan media dengan tepat dapat mendukung dalam mendidik anak dalam menghafal al-Qur'an seperti VCD, MP3, murattal, video-video terkait al-Qur'an dan Film-film Islami serta bukubuku yang mendukung kecintaan anak terhadap al-Qur'an. Terlebih jika program menghafal al-Qur'an mendapatkan dukungan dari para orang tua, yakni orangtua membantu anak dalam murajaah atau mengulang hafalan di rumah.

Selanjutnya faktor penghambat penerapan metode Tabarak dalam menghafal al-Qur'an Juz 30 di Sekolah Tahfidz Al-Husna Balita dan Anak Makassar yaitu: 1) kefokusan anak kurang dalam memperhatikan murattal yang telah diputarkan; 2) kehadiran anak ke sekolah yang terlambat atau tidak hadir ke sekolah; 3) kesibukan orangtua sehingga kurang terkontrolnya muraja'ah hafalan anak di rumah; 4) Hanya tiga ustadzah yang berlisensi atau memiliki sertifikat pelatihan metode Tabarak yakni dari pengajar di kelas Anak. Sedangkan ketiga ustadzah pada kelas balita belum memiliki lisensi (hanya dilatih oleh rekan pengajar yang sudah berlisensi tersebut) (hasil wawancara dengan AB), sehingga peneliti memerlukan second opinion (pendapat ahli) dari pengajar metode Tabarak berlisensi dari sekolah Hafidz Qur'an Savety, yakni ustadzah LM untuk memvalidasi prosesnya. Serta 5) hasil validasi menunjukkan bahwa pembelajaran pada rumah Qur'an Al Husna tidak menerapkan 2 file video yang ada pada metode Tabarak yaitu video tikror dan video muraja'ah yang dapat disebabkan oleh beberapa pertimbangan internal, sehingga tidak maksimal dalam mendisiplinkan anak dan pembelajaran tahfiz (Lubis dan Ismet, 2019). Semua faktor ini akan efektif apabila ustadzah yang mengajar lebih bijaksana dan tegas lagi dalam menghadapi anak balita serta adanya kerjasama yang baik antara orangtua dengan ustadzah yang mengajar. Apabila semuanya dijalankan dengan baik maka, proses pembelajarannya akan berjalan dengan baik dan efektif meskipun anak jarang masuk sekolah tetapi di rumah tetap diadakan muraja'ah kepada anak (hasil wawancara dengan LM).

Hal ini dikuatkan dengan teori dari (Qomariah dan Irsyad, 2016) mengenai faktor penghambat dalam mendidik anak menghafal al-Qur'an yaitu: 1) anak usia dini masih ingin bermain karena menyenangkan bagi anak, 2) anak sakit merupakan kondisi yang dapat menghambat dalam proses menghafal al-Qur'an yang akan terhenti sementara waktu, sehingga hafalan anak tidak bertambah, 3) kesibukan orangtua dapat mengurangi waktu dalam membimbing anak menghafalkan al-Qur'an, serta 4) Dr. kamil telah mengatakan bahwasanya, jika ingin mencapai hasil maksimal dari metode Tabarak ini, semua SOP Tabarak harus diterapkan metode Tabarak wajib diterapkan.

Keberhasilan menghafal al-Qur'an pada metode Tabarak dilihat dari 
kerjasama antara orangtua dan pihak sekolah atau ustadzah yang mengajar di kelas. Metode ini pada level 1 memiliki target hafalan juz 30 yang diselesaikan dalam jangka waktu 6 bulan. Kesuksesan anak dalam mencapai yang diharapkan sangat dipengaruhi oleh dua pihak yakni orangtua dan ustadzah. Pada pelaksanaan metode ini, orangtua harus mempunyai komitmen untuk mendatangkan anak di waktu yang tepat serta rajin menghafal, mengontrol hafalan anak, serta rajin memuraja'ahkan anak ketika di rumah, orangtua juga harus melakukan pemantauan kepada anak dan juga kartu mutab'ah anak setiap harinya. Kerjasama harus terjalin antara kedua orangtua dan pihak sekolah demi mensukseskan seluruh jenjang yang akan dilalui anak. Pada sela-sela pelaksanaannya orangtua dikirimkan berbagai informasi yang bersifat bimbingan para orangtua yang dimaksudkan untuk menumbuhkan kesadaran keluarga akan urgensi periode usia dini. Pada setiap tahapan metode Tabarak memiliki kerangka waktu, media pembelajaran dan berbagai informasi kepada kedua orangtua, buku muraja'ah anak yang dievaluasi orangtua setiap harinya. Membimbing dan memonitoring hafalan anak di rumah serta mengirimkan bukti rekaman muraja'ah berupa voice note ke grup whatsapp yang dikelola pihak sekolah. Orangtua juga memiliki kewajiban mengantar jemput anak ke sekolah tepat waktu dan membatasi anak dalam menonton TV atau bermain gadget.

\section{KESIMPULAN}

Penerapan proses pembelajaran metode Tabarak dalam menghafal al-Qur'an pada Sekolah Tahfidz Al-Husna Balita dan Anak Makassar dengan metode Tabarak memiliki buku panduan khusus yang disusun oleh Kamil el-Laboody. Program Tahfidz menghafal al-Qur'an dengan menggunakan metode Tabarak pada anak balita di Sekolah Tahfidz Al-Husna Balita dan Anak Makassar dilaksanakan dengan mentalqinkan bacaan al-Qur'an dan muraja'ah hafalan dengan memperdengarkan murattal yang memanfaatkan media elektronik berupa TV, MP3, Speaker, dan MIC. Adapun faktor pendukung pembelajaran berupa ruangan kondusif, ustadzah yang ramah, tahsin dan tahfidz ustadzah yang bagus, sarana dan prasarana memadai, serta dukungan orangtua dalam kegiatan menghafal al-Qur'an. Sedangkan lima faktor penghambat pembelajaran berupa kefokusan anak kurang karena bermain dalam kelas saat menghafal, kehadiran anak di sekolah, kesibukan orangtua yang tidak mengontrol dan muraja'ahkan anaknya, sekolah tidak menerapkan (tidak memakai) 2 file video yang ada pada metode Tabarak (Tikror dan muraja'ah) sehingga tidak maksimal terutama kedisiplinan anak, serta ketiga ustadzah yang belum berlisensi. 


\section{DAFTAR PUSTAKA}

Ahmad, A. A. (2017) Usia Para Ulama Ketika Hafal al-Qur'an, Ma'had Tahfidz alQur'an. Artikel (Online),(http://www.ummuwaraqah.com/2017/11/usia-paraulama-ketika -hafal-al-quran.html), diakses 15 Mei 2020.

Ariyanti, T. (2016). Pentingnya Pendidikan Anak Usia Dini Bagi Tumbuh Kembang anak, Jurnal Dinamika Pendidikan Dasar. PGPAUD Universitas Muhammadiyah Purwakerto (Online), Vol. 8 No. 1 Tahun 2016 (http://jurnalnasional.ump.ac.id/index.php/Dinamika/article/view/943 /881), diakses 29 Juni 2020.

Aziz, A. J. (2017). Pengaruh Menghafal al-Qur'an Terhadap Pembentukan Karakter Peserta Didik di Roudhotul Atfal (RA) Jamiatul Qurra Cimahi, Jurnal IImiah Tumbuh Kembang Anak Usia Dini (Online), Vol. 2 No. 1 Tahun 2017 (http://ejournal.uin suka.ac.id/tarbiyah/index.php/goldenage/art icle/view/1357), diakses 29 Juni 2020.

Gade, F. (2014). Implementasi Metode Takrar dalam Pembelajaran Menghafal AlQur'an. Jurnal Didaktika (Online), Vol. XIV No. 2 Tahun 2014 (http://jurnal.arraniry.ac.id/index.php/didaktika/article/download/512/428), diakses 16 Juni 2019).

Hasyim, L. S. (2015). Pendidikan Anak Usia Dini (PAUD) dalam Perspektif Islam, STAI Miftahul 'Ula Kertosono Nganjuk. Jurnal Lentera: Kajian Keagamaan, Keilmuan dan Teknologi (Online), Vol. 1 No. 1 Tahun 2015 (http://ejournal.uin suka.ac.id/tarbiyah/index.php/goldenage/article/view/13 57), diakses 29 Juni 2020).

Hidayah, A. (2017). Metode Tahfidz al-Qur'an untuk Anak Usia Dini, UIN Sunan Kalijaga Yogjakarta, Jurnal Studi IImu-ilmu al-Qur'an dan Hadis (Online), Vol. 18 No. 1 Tahun 2017 (http://ejournal.uin suka.ac.id/ushuluddin/alquran /article/download/1503/1243), diakses 29 Juni 2020.

Hariyanti, W.E. ( 2017). Metode Menghafal Al'Qur'an Pada Anak Usia Dini Tesis (Online), Yogjakarta: Fakultas IImu Tarbiyah dan Keguruan, UIN Sunan Kalijaga. (http://digilib.uin-suka.ac.id/26683/1/1520431001_BAB-I_IV-atauV_DAFTAR-PUSTAKA.pdf), diakses 20 Juni 2019.

Iryani, E. (2017). Al-qur'an dan IImu Pengetahuan. Jurnal IImiah Universitas Batanghari Jambi (Online), Vol. $17 \quad$ No. 03 Tahun 2017 (https://media.neliti.com/media/publications/225319-al-quran-danilmu-pengetahuan-86bc1365.pdf), diakses 14 Juni 2019.

Khoiriyah, N. (2016). Metode menghafal Al-qur'an. Skripsi (Online). Salatiga: Fakultas Tarbiyah dan IImu Kependidikan IAIN Salatiga (http://erepository.perpus.iainsalatiga.ac.id/1456/1/skripsi.pdf), diakses 19 Juli 
2019.

Khomaeny, F. F. E. R. Hikmah N.R. Yunitasari, N. dan Maulana A. (2018). Bermain Ludo King untuk Meningkatkan Kemampuan Sosial Anak Usia Dini, Universitas Muhammadiyah Tasikmalaya. Jurnal Pendidikan: Early Childhood (Online), Vol. 2 No. 2 Tahun 2018 (https://journal.umtas.ac.id/inde x.php/EARLYCHILDHOOD/article/view/285), diakses 29 Juni 2020.

Latif, M., Zukhairina, Zubaidah, R., dan Afandi, M. (2016). Orientasi Baru Pendidikan Anak Usia Dini: Teori dan Aplikasinya. Jakarta: Prenadamedia Group.

Lubis, A. M. dan Ismet, S. (2019). Metode Menghafal al-Qur'an pada Anak Usia Dini di Tahfidz Center Darul Hufadz Kota Padang. Journal on Early Childhood (Online), Vol. 2 No. 2 Tahun 2019 (https://aulad.org/index.php/aul ad/article/view/30), diakses tanggal 1 maret 2020.

Masduki, Y. (2018). Implikasi Psikologi Bagi Penghafal Al-qur'an. Jurnal Medina Te (Online), $\quad$ Vol. $18 \quad$ No. $01 \quad 2018$ (http://jurnal.radenfatah.ac.id/index.php/medinate/article/view/2362/1747) , diakses 11 Juli 2019.

Masyhud, R. F. dan Husnur, I. (2016). Rahasia Sukses 3 Hafidz Qur'an Cilik Mengguncang Dunia. Jakarta: Zikrul.

Mufarizuddin, F.M. (2018). Useful of Clap Hand Games for Optimalize Cogtivite Aspects in Early Childhood Education. Jurnal Obsesi: Jurnal Pendidikan Anak Usia Dini (Online), Vol. 2 Issue 2 Tahun 2018 (https://obsesi.or.id/index.php/obsesi/article/download/76/78), diakses 29 Juni 2020.

Maesaroh, S. (2013). Peranan Metode Pembelajaran Terhadap Minat dan Prestasi Belajar Pendidikan Agama Islam. Jurnal Kependidikan (Online), Vol. 1 No. 1 Tahun 2013 (http://ejournal.iainpurwokerto.ac.id/index.php/jurnalkepe ndidikan/article/view/536), diakses 29 Juni 2020.

Sugiyono. (2016). Metode Penelitian Pendidikan: Pendekatan Kuantitatif, Kualitatif dan R\&D. Bandung: Alfabeta.

Sayyid, S. A. (2013). Balita pun Hafal al-Qur'an. Solo: PT Tiga Serangkai Pustaka Mandiri.

Samuel. (2017), Tujuan Pendidikan yang Penting untuk Diketahui, Surabaya: Universitas Ciputra (Online), (http://ciputrauceo.net/blog/2016/2/25/tujuanpendidikan-yang-penting-untuk-diketahui), diakses 29 Juni 2020.

Yulidesni, Kurniah, N., dan Novrinda. (2017). Peran Orang tua dalam Pendidikan Anak Usia Dini Ditinjau dari Latar Belakang Pendidikan, PG- PAUD FKIP UNIB, 
Jurnal Potensia (Online), Vol. 2 No. 1 Tahun 2017 (https://ejournal.unib.ac.id/index.php/potensia/article/download/3721/196 9), diakses 29 Juni 2020.

Qomariah, N. dan Irsyad, M. (2016). Metode Cepat dan Mudah agar Anak Hafal AlQur'an. Yogjakarta: Semesta Hikmah. 